\title{
BOOKLINE: UMA FERRAMENTA TECNOLÓGICA A SERVIÇO DA AVALIAÇÃO DE TRABALHOS CIENTÍFICOS EM EVENTOS ACADÊMICOS
}

\author{
BOOKLINE: A TECHNOLOGICAL TOOL AT SERVICE OF SCIENTIFIC PAPERS \\ EVALUATION IN ACADEMIC EVENTS
}
BOOKLINE: UNA HERRAMIENTA TECNOLÓGICA A SERVICIO DE LA EVALUACIÓN DE TRABAJOS CIENTÍFICOS EN EVENTOS ACADÉMICOS

\section{RESUMO}

\section{Cênio Back Weyh ${ }^{1}$ Fernando Luis Oliveira ${ }^{2}$}

O uso das tecnologias vem sendo cada vez mais frequente no ensino. Os softwares que facilitam o trabalho docente enquanto recursos tecnológicos também podem ser utilizados para as demais faces da educação. Os eventos científicos são fundamentais para o aprendizado discente, característicos no ensino superior. Considerando-se a complexidade em coordenar um evento pela quantidade de pessoas envolvidas, os meios de envio dos trabalhos para análise e sua avaliação durante o encontro buscou-se introduzir ferramentas tecnológicas. Neste sentido, desenvolveu-se um software para gerenciar eventos científicos provendo uma interface para organização da avaliação de trabalhos e critérios de avaliação, bem como a gerência de avaliadores e suas áreas temáticas de atuação. O software intitulado Bookline foi projetado para ambientes móveis, possibilitando aos avaliadores liberdade para se locomoverem livremente durante as avaliações, recebendo informações adicionais sobre cada critério de avaliação, a fim de viabilizar o mais amplo espectro na constituição da nota do trabalho. Ao final das avaliações, o avaliador enviou suas considerações ao servidor central, que processou e compilou seus dados e dos demais avaliadores identificando se o trabalho foi aceito.

PALAVRAS-CHAVE: Tecnologia e educação. Software. Evento científico. Avaliação.

\begin{abstract}
The use of technologies has been more common each day in teaching. The softwares that facilitate the teacher's work as a technological source can also be used for other aspects of education. The scientific events are fundamental for the particular student's learnings in higher education. Considering the complexity of coordinating an event due to the number of people involved and the means of sending works for analysis and their evaluation during the event, we looked forward to developing technological tools. In this sense, we developed a software to manage scientific events providing an interface for the organization of the works' evaluation and of the criteria for evaluation, as well as the management of evaluators and their thematic areas of performance. The software named Bookline was designed for mobile environments, making it possible for the evaluators to wander around freely during the evaluations, getting additional information about each criterion of evaluation, in order to enable the widest spectrum in the constitution of the work's mark. At the end of the evaluations, the evaluator sends his considerations to the central server, that processes and compiles its data and from the rest of the evaluators identifying if the work was accepted.
\end{abstract}

KEYWORDS: Technology and education. Software. Scientific event. Evaluation.

\footnotetext{
${ }^{1}$ Doutor em Educação pela Universidade do Vale do Rio dos Sinos. Docente titular Universidade Regional Integrado do Alto Uruguai e das Missões. E-mail: ceniow@ santoangelo.uri.br

${ }^{2}$ Especialista em Desenvolvimento de Software e Novas Tecnologias. Acadêmico do Programa de PósGraduação em Ensino Científico e Tecnológico - Mestrado Profissional. Professor do Instituto Federal Farroupilha. E-mail: fernando.oliveira@iffarroupilha.edu.br

Recebido em: 28/10/2016 - Aceito em: 29/11/2016
}

v.2 1 n.3




\section{RESUMEN}

El uso de las tecnologías se está haciendo cada vez más frecuente en la enseñanza. Los softwares que facilitan el trabajo docente mientras recurso tecnológico también pueden ser utilizados para las demás faces de la educación. Los eventos científicos son fundamentales para los aprendizajes discentes característicos en la enseñanza superior. Considerándose la complexidad para coordinar un evento por la cantidad de personas involucradas y los medios de envío de los trabajos para análisis y evaluación durante el evento, se ha buscado introducir herramientas tecnológicas. En este sentido, se ha desarrollado un software para administrar eventos científicos proveyendo una interfaz para organizar la evaluación de trabajos y poner criterios, así como la administración de evaluadores y sus áreas temáticas de actuación. El software titulado Bookline fue proyectado para ambientes móviles, posibilitando a los evaluadores la libertad para desplazarse libremente durante las evaluaciones, recibiendo informaciones adicionales sobre cada criterio de evaluación, con objeto de viabilizar el más amplio espectro en la constitución de la calificación del trabajo. Al fin de las evaluaciones, el evaluador envió sus consideraciones al servidor central, que procesó y compiló sus datos y de los demás evaluadores, identificando si fue aceptado el trabajo.

PALABRAS CLAVE: Tecnología y educación. Software. Evento científico. Evaluación.

\section{A Título de Introdução}

As Tecnologias da Informação e Comunicação (TICs) estão presentes em todas as faces da sociedade contemporânea. A sociedade moderna não pode ignorar as transformações que as TICs oferecem e, especialmente a escola, tem o dever de explorar seu potencial e acompanhar essas evoluções e transformações. É na escola que os alunos se apropriam de conhecimentos diversos e questões como aprendizagem, informação e conhecimento que se entrelaçam formando um universo que nem sempre é compreendido por todos os alunos, carecendo assim, de novas ferramentas para facilitar o ensino e a transmissão de conhecimento. Neste contexto, é fundamental que a escola faça uso das referidas ferramentas para melhorar o processo educacional, propondo novos meios de aprendizagem com fim de estreitar o relacionamento com os estudantes, instigando e desafiando-os constantemente.

Os alunos, desde cedo, vivenciam uma sociedade tecnológica, sistematizada, que está em constante evolução, portanto, é inevitável o convívio com as TICs. Desta forma, a escola deve escolher com sabedoria, dentre todas as possibilidades oferecidas, quais tecnologias podem realmente contribuir com a formação dos alunos ou auxiliar no processo pedagógico, sem descaracterizá-la como uma instituição formadora.

Assim, compreende-se que a tecnologia aplicada à educação pode se tornar uma aliada valiosa, propondo aulas mais interativas e mais atrativas, como esclarece Souza (2010, p. 1):

Aulas modernizadas pelo uso de recursos tecnológicos têm vida longa e podem ser adaptadas para vários tipos de alunos, para diferentes faixas etárias e diversos níveis de aprendizado. O trabalho acaba tendo um retorno muito mais eficaz. É importante, no entanto, que haja não apenas uma revolução tecnológica nas escolas. É necessária a revolução na capacitação docente, pois a tecnologia é algo ainda a ser desmistificado para a maioria dos professores. 
O professor tem um papel fundamental na conciliação entre a tecnologia e a sala de aula, pois cabe a ele ser o mediador do conhecimento. No entanto, muitos professores ainda acreditam que a principal e única formação importante é titular-se num curso de graduação de nível superior. Trata-se de uma perspectiva conteudista que resiste às novas formas de ensinar e aprender. Neste sentido, alguns profissionais sentem dificuldades em perceber as inovações e aventurar-se. Ignoram os avanços tecnológicos, seja por comodismo, ou por falta de tempo, ou por falta de oportunidades de acesso qualificado, ou até mesmo por receio das novas tecnologias. De acordo com Valente (1997, p. 19), "o mundo atual exige um profissional crítico, atuante, colaborador, com capacidade de pensar, de aprender a aprender, de trabalhar em grupo, de conhecer o seu potencial intelectual". Desta forma, o profissional comprometido deve-se manter em constante atualização e ser um eterno aprendiz.

Durante a graduação, os educandos recebem conhecimento tecnológico existente naquele período de sua formação, mas, com passar do tempo novas tecnologias surgem impulsionadas pelas TICs, como acontece com os softwares. Eles são desenvolvidos para fins diversos, seja para solucionar problemas, seja para automatizar situações rotineiras da escola, do docente ou do contexto escolar em geral. Os aplicativos podem ser bastante flexíveis e atender a demandas distintas. Portanto, uma formação básica já não basta. As novas tecnologias, as necessidades e os desafios do dia-a-dia obrigam a buscar outras alternativas para as soluções do cotidiano.

Neste sentido, o computador, smartphones, tablets e a Internet são instrumentos fundamentais para despertar a curiosidade e instigar a utilização de tecnologias na sala de aula, devido aos inúmeros recursos disponíveis, tornando-os um complemento educacional e essencial nos demais setores da sociedade. Valente (1997, p.21) afirma que o uso consciente e inteligente do computador na educação possibilita uma revolução no modelo tradicional. De acordo com o autor, "a partir deste recurso os alunos podem: criar, pensar, refletir, manipular a informação e construir o conhecimento".

\section{Eventos Científicos}

No ambiente universitário os eventos científicos são frequentes e muito utilizados para a qualificação do conhecimento dos alunos, além de recomendados pelos órgãos federais, como o Ministério da Educação (MEC). Tais eventos aportam uma contribuição fundamental para educação superior, pois provocam nos acadêmicos o desejo de aperfeiçoamento nas mais diversas áreas do conhecimento. Neste sentido, também induzem o interesse para realizar pesquisas e escrever resumos, artigos, compartilhando-os nas apresentações. Desta forma, capitalizam-se os currículos, uma exigência do mercado de trabalho e inclusive do universo acadêmico.

Durante a formação, a produção de artigos ainda é frequentemente exigência de algumas disciplinas como requisito parcial à nota final. Igualmente em cursos de graduação e

\begin{tabular}{l|l|l|l|l|l|l} 
(C) Rev. Inter. Educ. Sup. & Campinas, SP & v.2 & n.3 & p.501-517 & set./dez. 2016 & ISSN 2446-9424
\end{tabular}


pós-graduação, artigos podem ser, inclusive, requisitos parciais para obtenção do título, considerando-se sua importância para a ciência. Para Kuhn (1998, p. 40),

\begin{abstract}
A teoria do conhecimento científico é necessária para a compreensão da evolução da ciência, em novas descobertas. Na contemporaneidade, os escritos científicos constituem de manuais ou reflexões, que versam sobre os acontecimentos passados da vida científica. De maneira regular, somente nos primeiros estágios do desenvolvimento das ciências, anteriores ao paradigma, o livro continha a mesma realização profissionais que ainda conserva em outras áreas abertas à criatividade.
\end{abstract}

Os eventos científicos têm como objetivo principal reunir o maior número de profissionais, estudantes e interessados da área abordada para a troca de conhecimentos, experiências e informação, sendo fundamentais para muitas profissões. Na concepção de Campello (2000, p. 60),

[...] os eventos científicos podem desempenhar diversas funções: encontros como forma de aperfeiçoamento de trabalhos científicos, uma vez que os trabalhos apresentados mudam substancialmente após apreciação nos eventos; encontro como reflexo do estado da arte, pois os trabalhos apresentados durante os eventos podem refletir o panorama da área e o perfil dos seus membros e encontros como forma de comunicação informal, pois as conversas informais com seus pares constituem parte importantes eventos.

Os referidos encontros possibilitam o acesso mais fácil e rápido às novidades das respectivas áreas, sendo um espaço onde ocorre uma vasta troca de experiências e conhecimentos socialmente construídos, favoráveis à atualização dos profissionais.

Neste sentido, Kuhn (1996, apud TACHIBANA; PAVANI; BARIANI, 2004, p.90) destaca que

[...] as atividades e experiências vivenciadas fora da sala de aula trazem inúmeros benefícios ao universitário, tais como maior segurança, autoestima e valores altruísticos. [...] é imprescindível ao estudante o reconhecimento por intermédio da divulgação pública de seu trabalho, seja através da publicação em revistas e periódicos, seja pela apresentação em congressos e seminários.

Para aqueles que costumam produzir artigos com a finalidade de apresentá-los em eventos científicos é necessária atualização constante, tendo sempre ideias novas para as produções. Assim também escrevem Carmo e Prado (2005, p. 131):

[...] a ciência é uma atividade social, e, portanto, precisa ser divulgada, debatida e refletida. A comunidade científica vista como produtora e disseminadora de novos conhecimentos científicos precisam estar constantemente em busca de informações atualizadas, e para isso precisa fazer uso dos mais diversos canais de comunicação científica que permitam a identificação dos conhecimentos já existentes.

Meadows (2000) classifica os canais de comunicação científicos como formais e informais. Para o autor, os livros e periódicos são os canais formais de comunicação, e os canais informais remetem à comunicação, a qual ocorre através de expressões como a fala, que não possui registro. $\mathrm{O}$ autor afirma: "Os congressos e conferências são o protótipo da interação informal. A interação oral varia de uma conferência pronunciada diante de uma

\begin{tabular}{l|l|l|l|l|l|l} 
(C) Rev. Inter. Educ. Sup. & Campinas, SP & v.2 & n.3 & p.501-517 & set./dez. 2016 & ISSN 2446-9424
\end{tabular}


grande plateia até as conversas triviais durante a pausa para o cafezinho" (MEADOWS, 2000, p. 39).

Por sua vez, Targino (2000, p. 19) destaca que os canais formais e os canais informais servem a fins distintos quanto à operacionalização das pesquisas, no entanto, "ambos são indispensáveis à comunicabilidade da produção científica, pois são utilizados em momentos diversos e obedecem a cronologias diferenciadas".

Nos eventos científicos os pesquisadores trazem suas inovações e descobertas de maneira informal, permitindo aos participantes o acesso às informações de forma facilitada e rápida. Nestes encontros apesar de haver uma programação prévia disponibilizada antecipadamente, sempre o ouvinte pode se surpreender positivamente e negativamente quanto à qualidade. Ainda assim, muitas vezes há que acrescentar bons conhecimentos, como afirma Meadows (2000, p.139-140), “os participantes de congressos e conferências podem planejar antecipadamente contatos específicos, mas também ocorrerão em geral contatos imprevistos, porém úteis, durante o evento".

Para Ohira (2002, p. 73), "os eventos científicos são canais extremamente eficazes na disseminação do conhecimento" em função do movimento crescente da ciência e, portanto, um meio de divulgação com possibilidade de novas aprendizagens. Desta forma, apresentamse como um ambiente propicio para compartilhar e obter conhecimentos sobre uma determinada área.

Percebe-se nitidamente a importância dos eventos científicos, porém, sua organização demanda muito trabalho e dedicação, visto que as atividades não se resumem ao dia do encontro, mas também ao período que o antecede. Para que um trabalho seja apresentado, ele deve passar por uma série de etapas que vão desde a submissão, até a avaliação por pares da área de conhecimento, os quais emitem um parecer sobre a aprovação ou não da pesquisa submetida.

Levando em consideração a importância desses eventos e a complexidade em sua organização construiu-se um software que auxilia neste processo.

\section{O Software}

Com o intuito de facilitar a organização do processo avaliativo em eventos científicos, propôs-se a criação de uma ferramenta (software) de controle do fluxo de submissões, avaliações e apurações de resultados. O aplicativo Bookline é composto por dois módulos, sendo um módulo servidor, responsável pela entrada dos dados do evento e o outro módulo para dispositivos móveis (smartphones e tablets) encarregado de realizar a avaliação dos trabalhos. 
De forma geral, os avaliadores vão interagir com módulo móvel. Assim, durante a execução do evento, terão liberdade para locomover-se livremente, recebendo informações adicionais sobre cada critério de avaliação, a fim de viabilizar o mais amplo espectro na constituição da nota do trabalho. Ao final das avaliações o avaliador envia suas considerações ao servidor central, que processa e compila seus dados, identificando se o trabalho foi aceito ou criando um ranking com as melhores produções.

\section{Módulo Servidor}

O módulo servidor foi projetado para ser acessado através de um navegador de Internet. Essa abordagem propicia um ambiente mais amigável aos utilizadores do aplicativo. O objetivo deste módulo é fornecer uma central de controle para as informações que compõem um evento, tais como: o próprio evento, critérios de avaliação, trabalhos, tipos de trabalho, áreas temáticas, apuração de resultados e relatórios.

Para interagir com o sistema os utilizadores devem ser cadastrados na aplicação. Cada usuário é classificado de acordo com sua atuação na temática do evento, podendo ser avaliador ou autor de trabalhos. Para demonstrar a utilização desta aplicação, deve-se considerar um cenário fictício apresentado no quadro 1.

Quadro 1 - Utilizadores do sistema.

\begin{tabular}{|l|l|}
\hline Nome do utilizador (usuário) & Função \\
\hline Autor de trabalho A & Autor ou coautor \\
\hline Autor de trabalho B & Autor ou coautor \\
\hline Avaliador A & Avaliador \\
\hline Avaliador B & Avaliador \\
\hline Avaliador C & Avaliador \\
\hline
\end{tabular}

Fonte: Elaboração dos autores.

O Quadro 1 apresenta uma relação com três avaliadores e dois autores de trabalhos, cujos dados serão utilizados no exemplo proposto.

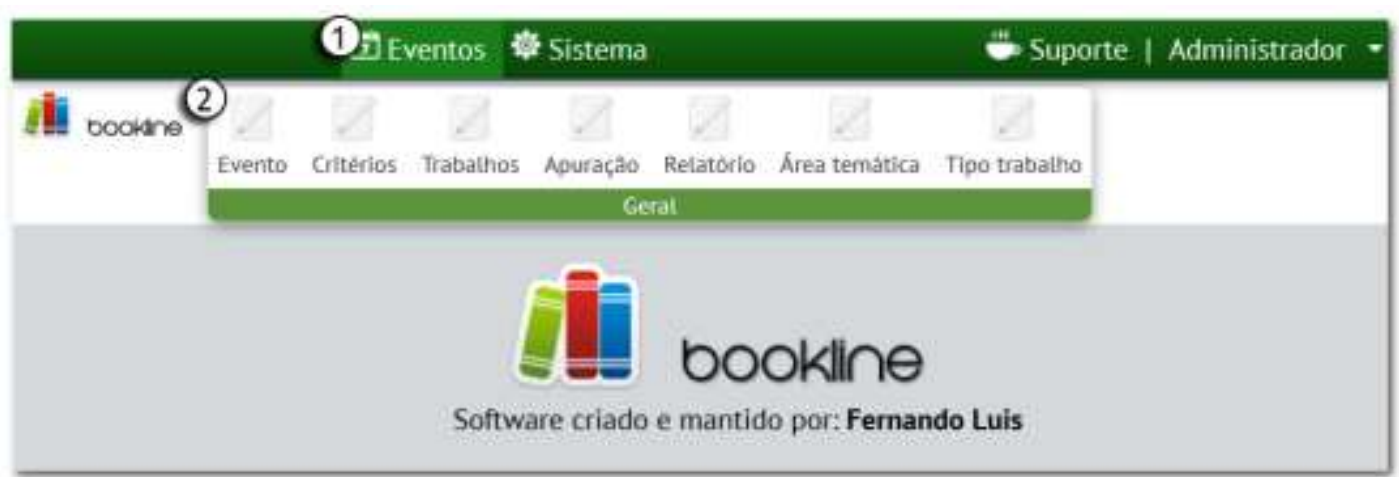

Figura 1 - Tela Inicial do Bookline.

Fonte: elaboração dos autores 
A figura 1 apresenta a tela inicial no módulo de gestão do Bookline. Observa-se que a imagem apresenta uma numeração, essa prática será adotada para esclarecer o funcionamento de cada componente apresentado conforme exposto no Quadro 2.

Quadro 2 - Utilizadores do sistema.

\begin{tabular}{|l|l|}
\hline Item & Definição \\
\hline 1 & $\begin{array}{l}\text { Representa o item de navegação geral da aplicação (menu). Ao clicar com mouse sobre o item } \\
\text { "Eventos" as funcionalidades ligadas ao evento científico são apresentadas. }\end{array}$ \\
\hline 2 & Opções de menu que representam as funcionalidades para gerir o evento. \\
\hline
\end{tabular}

Fonte: Elaboração dos autores.

A figura 2 representa a visão que o usuário dispõe para gerenciar um evento, servindo tanto para inclusão de novos itens quanto para edições.

O Quadro 3 detalha cada componente.

Quadro 3 - Definições sobre tela de evento.

\begin{tabular}{|c|l|}
\hline Item & Definição \\
\hline 1 & Botão utilizado para criar um novo evento; \\
\hline 2 & Botão para retornar a tela anterior (tela de listagem de eventos); \\
\hline 3 & $\begin{array}{l}\text { Botão para finalizar um evento. Quando finalizado, o evento não pode ser editado nem tampouco } \\
\text { receber novas avaliações; }\end{array}$ \\
\hline 4 & Descrição ou nome do evento científico; \\
\hline 5 & Período em que o evento acontecerá, sendo necessário definir a data de início e data de fim; \\
\hline 6 & Sigla ou nome abreviado que identifica o evento; \\
\hline 7 & $\begin{array}{l}\text { Esta opção indica se o evento trabalha ou não com critérios de avaliação ponderados, ou seja, } \\
\text { critérios que possuem pesos diferenciados para composição da nota; }\end{array}$ \\
\hline 8 & Botão que grava as informações do evento. \\
\hline
\end{tabular}

Fonte: Elaboração dos autores.

Após a inclusão de um evento é possível adicionar critérios de avaliação. Para isso, deve-se clicar na opção de menu "Critérios" conforme exposto na figura 1. Como resultado, tem-se a interface para gestão de critérios como apresenta a figura 3.

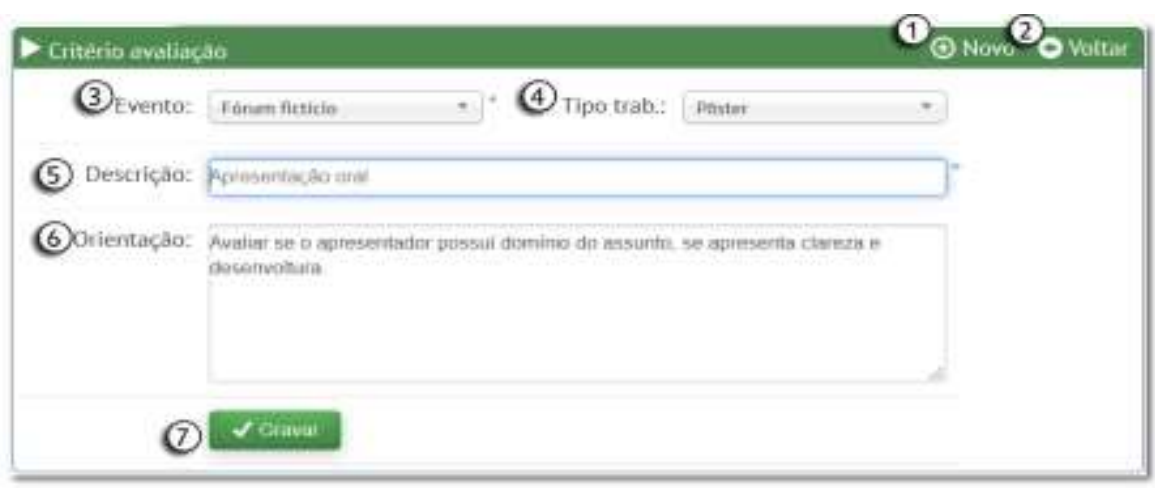

Figura 3 - Tela de manutenção de critérios de avaliação Fonte: Elaboração dos autores. 
Na figura 3 apresenta-se a interface para criação e edição de critérios de avaliação. Um critério corresponde a um item que o avaliador irá julgar nos trabalhos apresentados. Não há limites de critérios de avaliação, no entanto, cada critério deve obrigatoriamente estar associado a um evento e pode ser vinculado a um tipo de trabalho específico.

Um tipo de trabalho equivale a uma categoria na qual o trabalho é submetido, como por exemplo: pôster, relato de experiência, artigos, entre outros. A associação entre um critério e um tipo de trabalho implica que o critério será aplicado somente a trabalhos do tipo pré-definido. O Quadro 4 detalha esta interface.

Quadro 4 - Definições sobre tela de critérios de avaliação.

\begin{tabular}{|c|l|}
\hline Item & Definição \\
\hline 1 & Botão para incluir um novo critério; \\
\hline 2 & Botão para voltar à listagem de critérios; \\
\hline 3 & Caixa de seleção do evento, item obrigatório; \\
\hline 4 & Caixa de seleção do tipo de trabalho; \\
\hline 5 & Descrição ou nome do critério de avaliação; \\
\hline 6 & $\begin{array}{l}\text { A orientação é uma informação opcional, serve para facilitar a compreensão do avaliador quando } \\
\text { analisar o critério; }\end{array}$ \\
\hline 7 & Botão para gravar as informações. \\
\hline
\end{tabular}

Fonte: Elaboração dos autores.

Após a inclusão do evento e de seus critérios é necessário submeter ou incluir os trabalhos que serão avaliados. Para isso deve-se clicar sobre o item "Trabalhos" (figura 1), o qual é representado na figura 4.

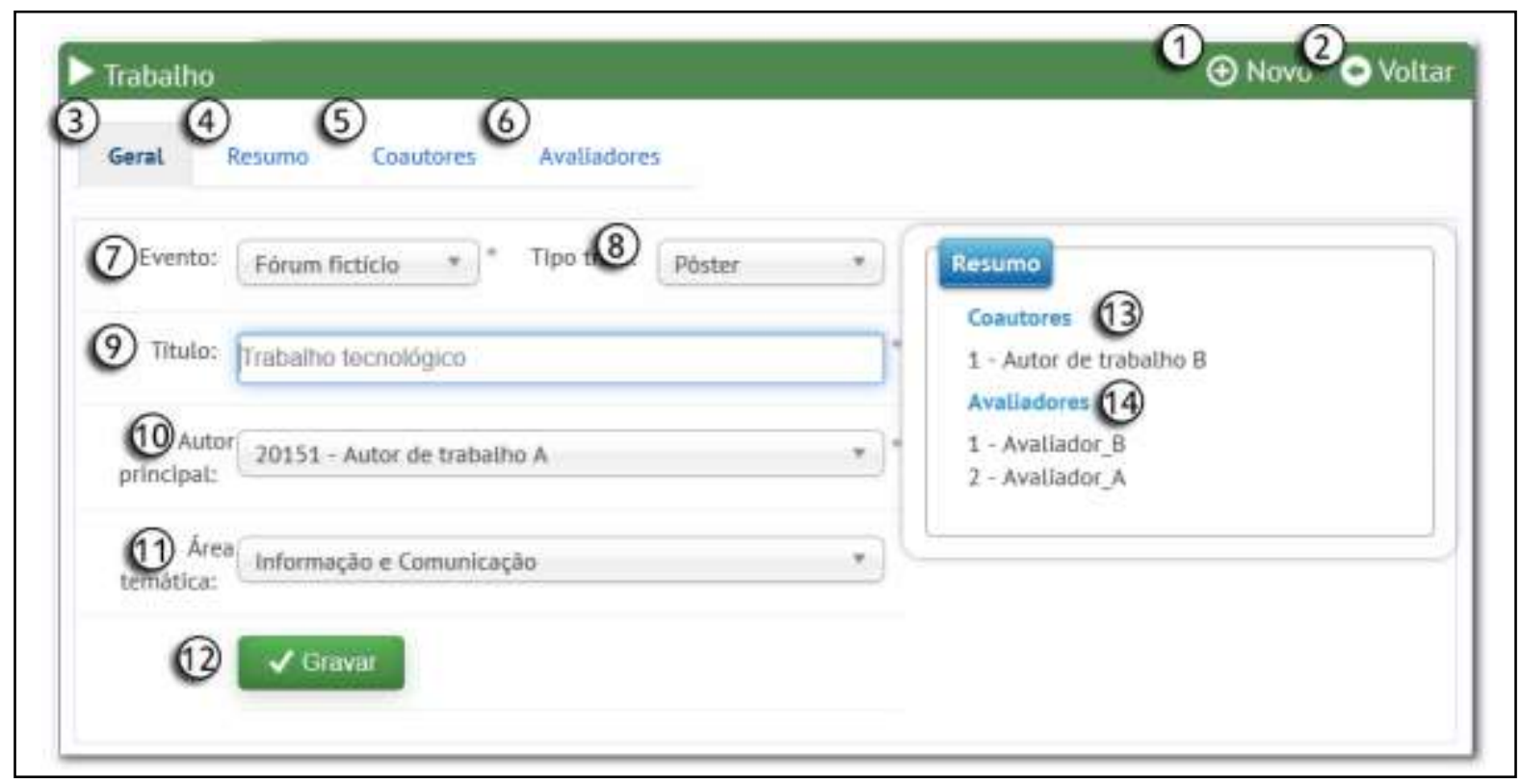

Figura 4 - Tela de manutenção de trabalhos.

Fonte: Elaboração dos autores.

n.3 
A interface para gestão dos trabalhos é um pouco mais extensa que as demais, pois nesta visão se concentram todas as informações pertinentes ao trabalho como: dados gerais do trabalho, resumo, coautores e avaliadores. No Quadro 5 apresenta-se o detalhamento de cada funcionalidade.

Quadro 5 - Definições sobre tela de trabalhos

\begin{tabular}{|c|l|}
\hline Item & Definição \\
\hline 1 & Botão para incluir um novo trabalho; \\
\hline 2 & Botão para voltar à listagem de trabalhos; \\
\hline 3 & $\begin{array}{l}\text { Aba geral: quando se clica sobre este item são apresentados os campos para gerir o trabalho, ou seja, } \\
\text { os campos que estão visíveis; }\end{array}$ \\
\hline 4 & Aba resumo: possibilita a inclusão do resumo e das palavras-chave (figura 5); \\
\hline 5 & Aba coautores: possibilita a inclusão dos coautores do trabalho (figura 6); \\
\hline 6 & Aba avaliadores: possibilita a seleção dos avaliadores que julgarão o trabalho (figura 7); \\
\hline 7 & Caixa de seleção para definição do evento para o qual o trabalho será submetido; \\
\hline 8 & Caixa de seleção para definição do tipo de trabalho; \\
\hline 9 & Título do trabalho; \\
\hline 10 & $\begin{array}{l}\text { Caixa de seleção para definir o autor principal do trabalho; neste item somente são listados os } \\
\text { utilizadores (usuários) agrupados como autores de trabalhos (Quadro 1); }\end{array}$ \\
\hline 11 & Caixa de seleção para definir a área temática na qual o trabalho se encaixa; \\
\hline 12 & Botão para gravar as informações; \\
\hline 13 & $\begin{array}{l}\text { Resumo informativo que demonstra quais são os coautores do trabalho, que são gerenciados pela aba } \\
\text { "coautores" (item 5 na figura 4); }\end{array}$ \\
\hline 14 & $\begin{array}{l}\text { Resumo informativo que demonstra quais são os avaliadores do trabalho, gerenciados pela aba } \\
\text { "avaliadores” (item 6 na figura 4). }\end{array}$ \\
\hline
\end{tabular}

Fonte: Elaboração dos autores.

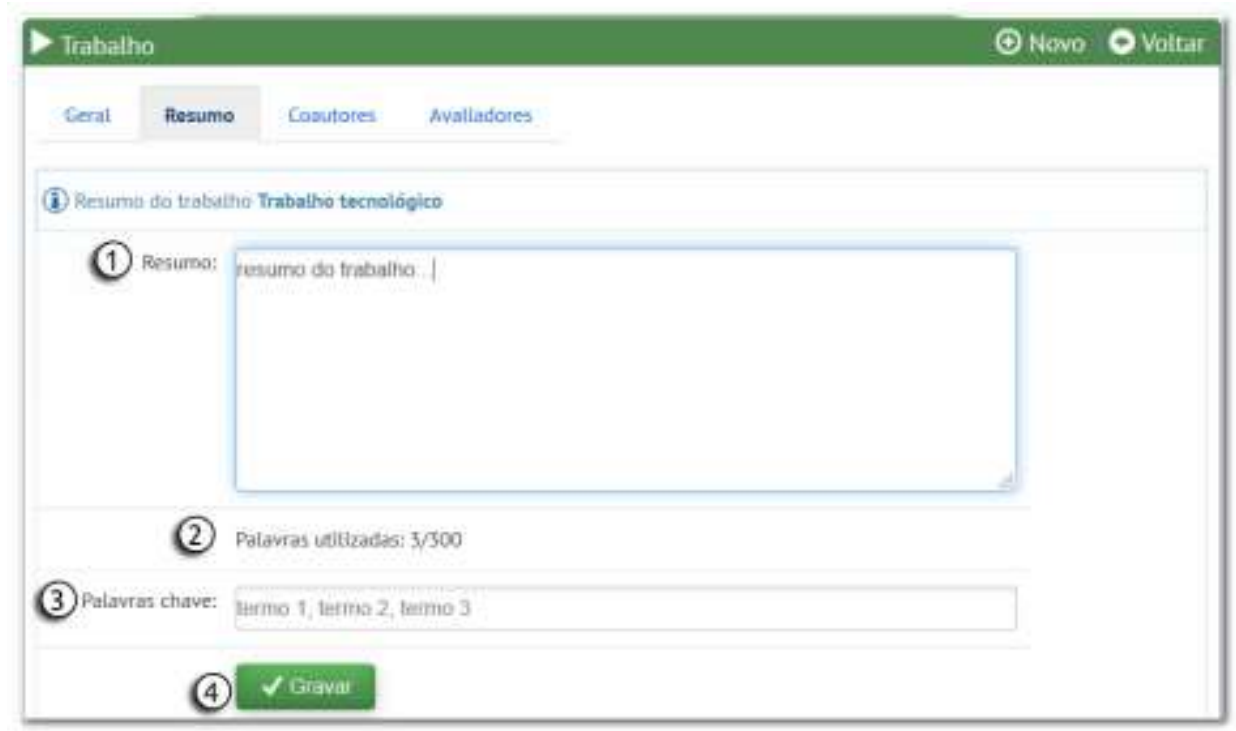

Figura 5 - Tela para entrada do resumo Fonte: Elaboração dos autores. 
A figura 5 apresenta a interface para inclusão do resumo do trabalho, que possui um limite de 300 (trezentas) palavras. O Quadro 6 detalha cada item.

Quadro 6 - Definições sobre tela de resumo.

\begin{tabular}{|c|l|}
\hline Item & Definição \\
\hline 1 & Campo texto para entrada do resumo; \\
\hline 2 & $\begin{array}{l}\text { Indicador de palavras utilizadas. A quantidade de palavras é contabilizada à medida que o usuário } \\
\text { redige o texto/resumo; }\end{array}$ \\
\hline 3 & Palavras-chave do resumo, que devem ser separadas por vírgula; \\
\hline 4 & Botão para gravar as informações. \\
\hline
\end{tabular}

Fonte: Elaboração dos autores.

Os coautores são pessoas que ajudaram a produzir o trabalho científico. Não há limite de coautores por trabalho, porém, somente podem ser adicionados como coautores os usuários classificados ou agrupados como autores (quadro 1).

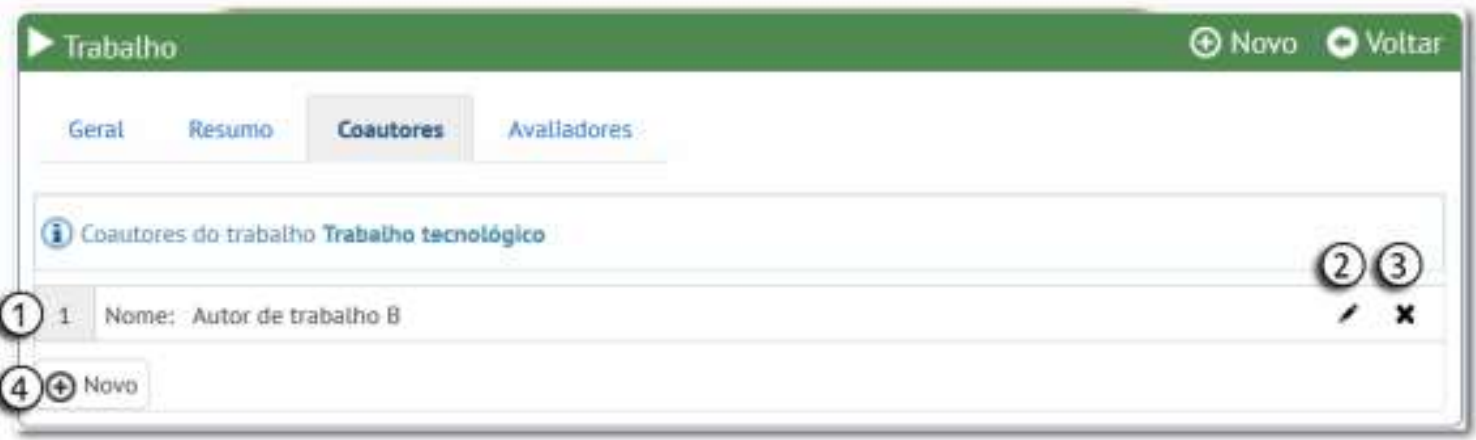

Figura 6 - Tela para manutenção de coautores

Fonte: elaboração dos autores

A figura 6 apresenta a interface para inclusão, edição e exclusão de coautores. Cada trabalho conta com um autor principal (selecionado através da aba "geral" - item 10 na figura 4) e nenhum ou muitos coautores. O Quadro 7 esclarece cada item.

Quadro 7 - Definições sobre tela de coautores.

\begin{tabular}{|c|l|}
\hline Item & Definição \\
\hline 1 & Representa a lista com todos os coautores associados ao trabalho; \\
\hline 2 & Botão para realizar a edição da associação do trabalho com o coautor; \\
\hline 3 & Botão para remover a associação entre o trabalho e o coautor; \\
\hline 4 & Botão para incluir um novo coautor ao trabalho. \\
\hline
\end{tabular}

Fonte: Elaboração dos autores.

Para finalizar a submissão do trabalho basta definir quais serão os avaliadores. Para um usuário ser considerado um avaliador ele deve ser agrupado como tal (Quadro 1). 


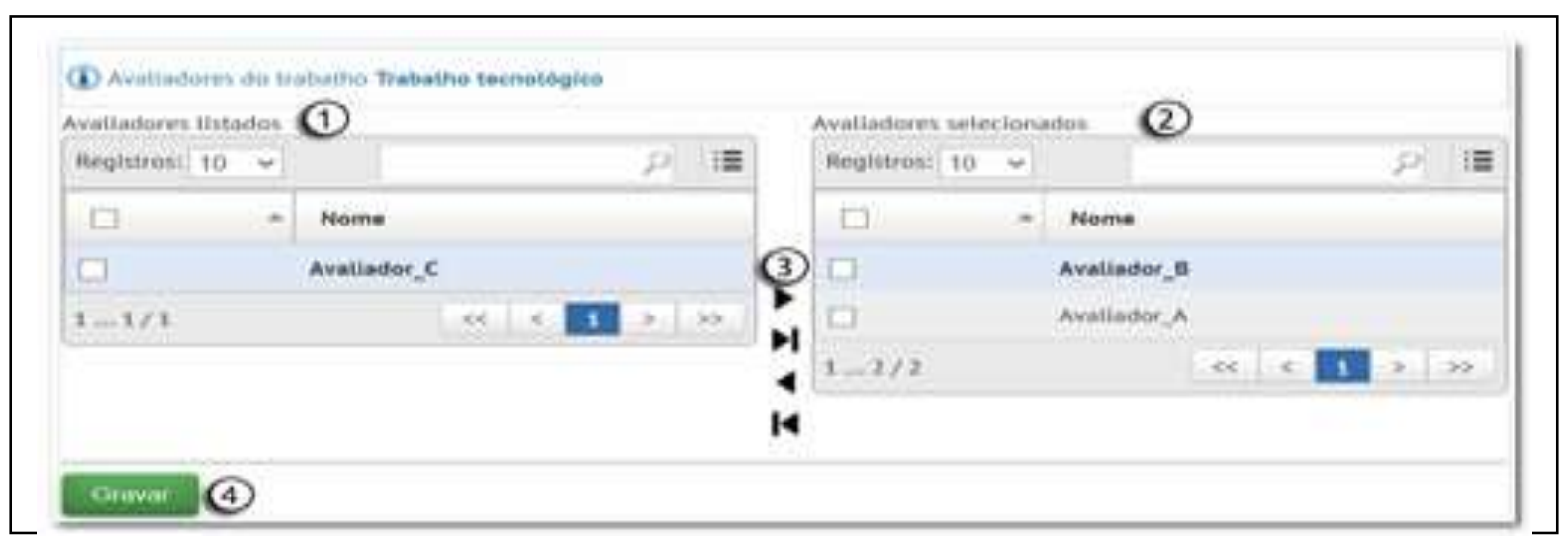

FIGURA 7 - Tela para definir avaliadores.

Fonte: Elaboração dos autores

Na figura 7 apresenta-se a interface para vincular os avaliadores a um determinado trabalho. Para que seja possível realizar a avaliação é necessário vincular ao menos um avaliador, desta forma, os itens listados à direita - "avaliadores selecionados" - serão os avaliadores deste trabalho, como detalhado no Quadro 8.

Quadro 8 - Definições sobre tela de seleção de avaliadores

\begin{tabular}{|c|l|}
\hline Item & Definição \\
\hline 1 & Listagem com todos os usuários que são avaliadores; \\
\hline 2 & Listagem com os usuários selecionados que serão os avaliadores do referido trabalho; \\
\hline 3 & $\begin{array}{l}\text { Representa botões de navegação, os quais possibilitam movimentar um avaliador da esquerda (lista } \\
\text { de avaliadores possíveis) para a direita (lista de avaliadores selecionados) ou vice-versa; }\end{array}$ \\
\hline 4 & Botão para gravar as informações. \\
\hline
\end{tabular}

Fonte: Elaboração dos autores.

\section{Módulo móvel}

O módulo móvel complementa o módulo servidor. Este item pode ser compreendido como um segundo aplicativo, podendo ser instalado em smatphones ou tablets que possuam como sistema operacional o Android. Este aplicativo, de forma geral, substituiu a antiga prancheta e os formulários de papel que os avaliadores utilizavam durante o julgamento dos trabalhos.

A parte móvel possui a habilidade de comunicar-se com o módulo servidor, portanto, toda informação apresentada e manipulada é provida pela parte servidora. Ao iniciar este sistema, o avaliador deve identificar-se através de um número de matrícula e senha, os quais são previamente definidos no lado servidor. 


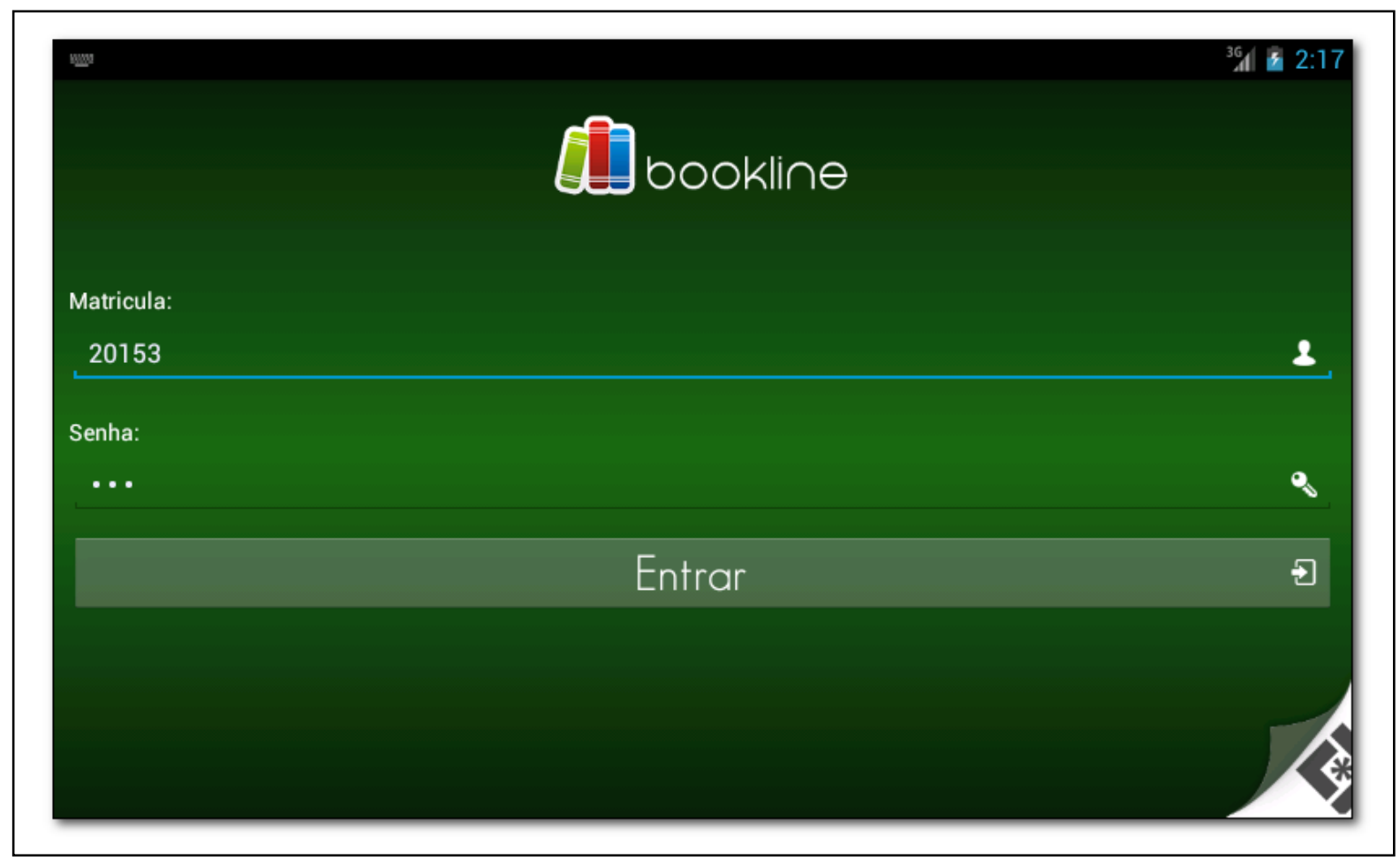

Figura 8 - Tela de identificação do usuário

Fonte: Elaboração dos autores

Uma vez identificado pelo sistema, o avaliador precisa, em um primeiro momento, realizar um processo denominado "sincronização". A sincronização compreende o fluxo pelo qual o dispositivo móvel receberá informações e enviará os dados referentes às avaliações realizadas. De uma forma resumida, ao sincronizar os trabalhos, os critérios de avaliação serão "baixados" para o dispositivo do avaliador. Assim, os registros de avaliação (notas) já realizados são enviados para serem processados.

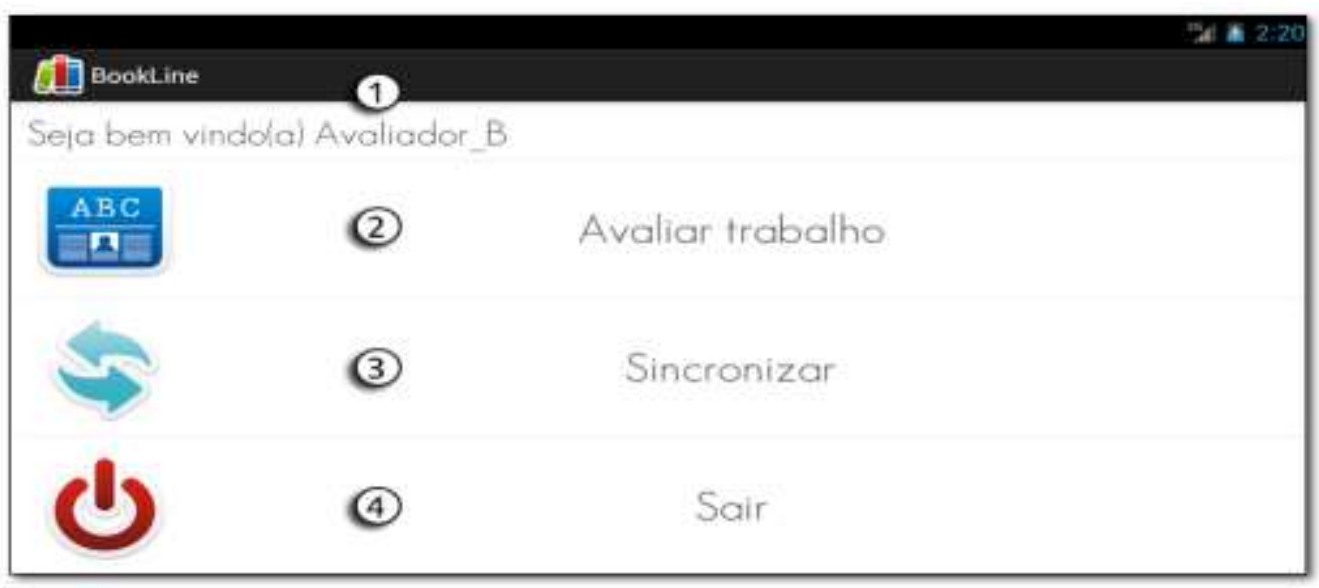

Figura 9 - Menu de funcionalidades do aplicativo móvel.

Fonte: Elaboração dos autores 
A figura 9 apresenta as funcionalidades presentes no aplicativo móvel. Por intermédio desta visão, o usuário pode navegar pela aplicação e acessar os recursos disponíveis, como detalhado no Quadro 9, por item.

Quadro 9 - Definições sobre a tela menu.

\begin{tabular}{|c|l|}
\hline Item & Definição \\
\hline 1 & $\begin{array}{l}\text { Apresenta uma informação textual sobre quem está operando a aplicação, ou seja, o nome do } \\
\text { avaliador; }\end{array}$ \\
\hline 2 & Botão do menu - possibilita abrir a tela que apresenta os trabalhos a serem avaliados (figura 10); \\
\hline 3 & Botão do menu - para acessar a funcionalidade de sincronização; \\
\hline 4 & Botão para encerrar o aplicativo; \\
\hline
\end{tabular}

Fonte: Elaboração dos autores.

Para realizar a avaliação dos trabalhos basta clicar sobre o item "Avaliar trabalho", que carregará a listagem de trabalhos disponíveis, conforme exposto na figura 10.

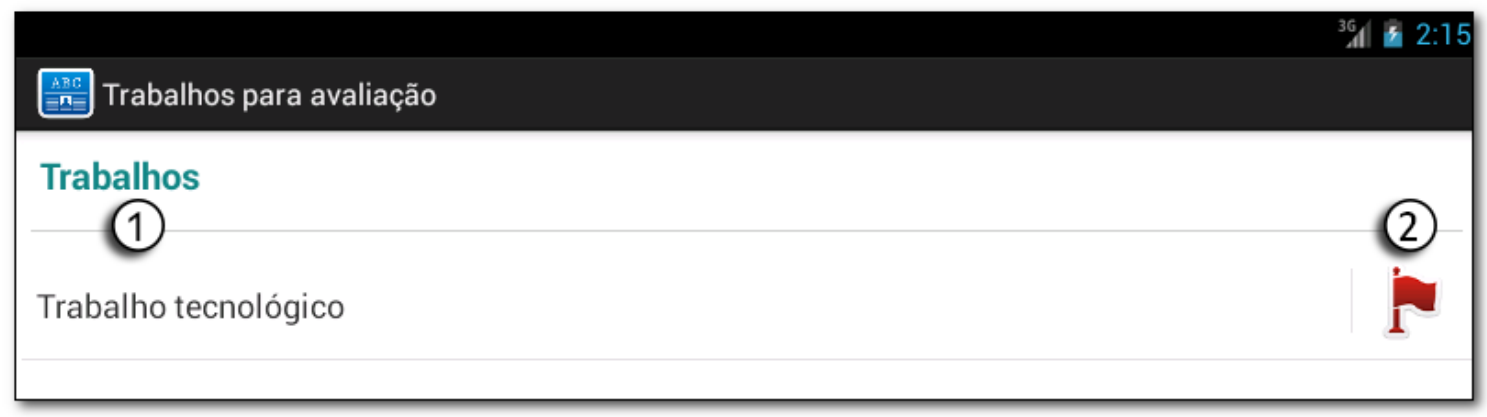

Figura 10 - Tela de listagem de trabalhos Fonte: Elaboração dos autores.

A Figura 10 demonstra a listagem de trabalhos que o avaliador deve julgar. Essa listagem é definida através da interface de associação entre avaliador e trabalho (figura 7). $\mathrm{O}$ Quadro 10 esclarece cada item.

QUADRO 10 - Definições sobre tela de listagem de trabalhos.

\begin{tabular}{|c|l|}
\hline Item & Definição \\
\hline 1 & Título do trabalho a ser avaliado - para avaliá-lo basta clicar sobre ele; \\
\hline 2 & $\begin{array}{l}\text { Ícone que representa se o trabalho já foi avaliado ou não; quando o trabalho é avaliado a imagem } \\
\text { fica verde. }\end{array}$ \\
\hline
\end{tabular}

Fonte: Elaboração dos autores.

A figura 11 apresenta a interface para avaliar o trabalho, efetivamente com base nos critérios definidos. 


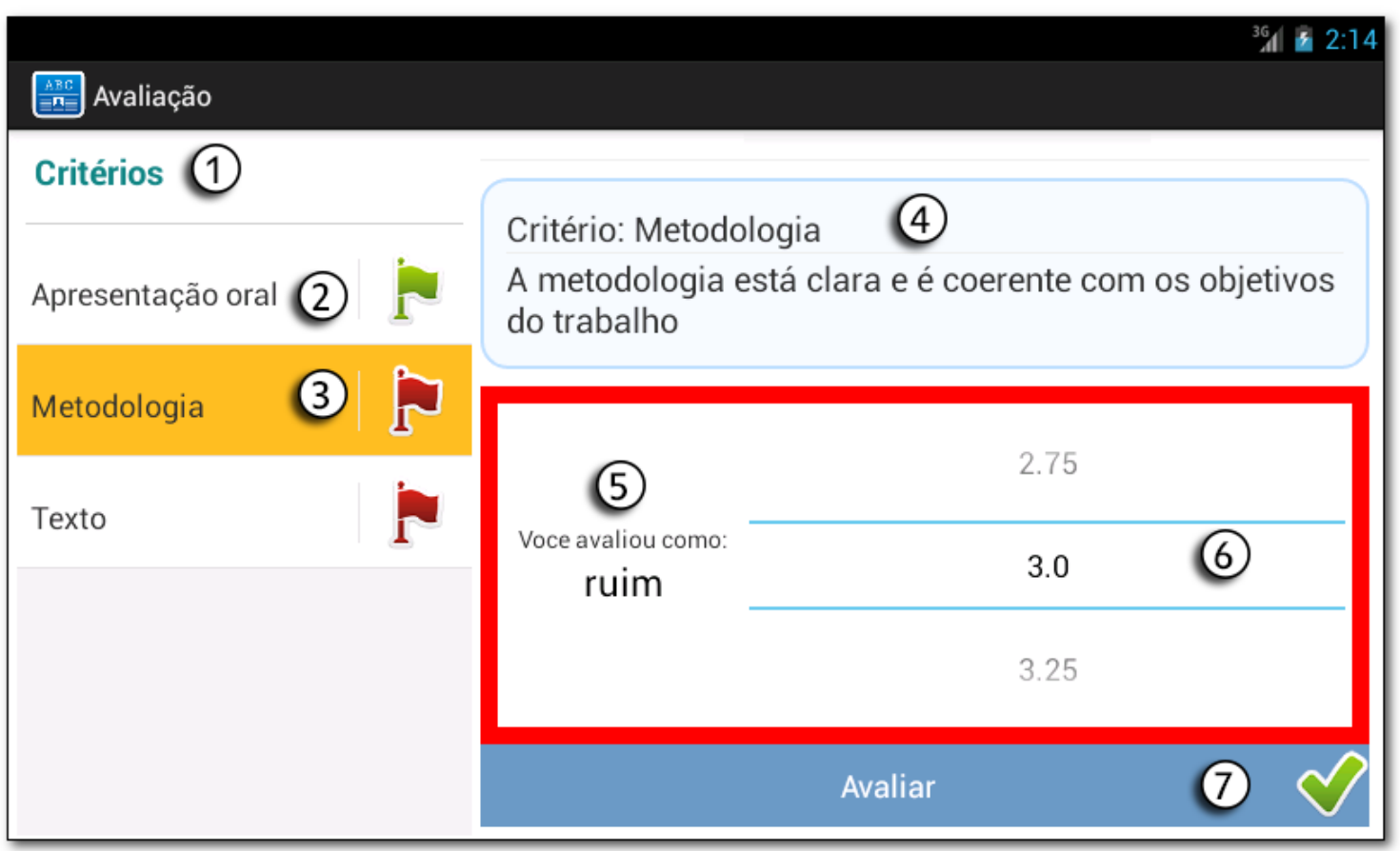

Figura 10 - Tela de avaliação de trabalho Fonte: Elaboração dos autores

Essa interface possibilita ao avaliador selecionar um critério e aferir um juízo de valor a ele, ou seja, atribui-se uma nota de 0 (zero) a 10 (dez). O avaliador conta com uma tela amigável e intuitiva, que o auxilia com sinais visuais acerca de suas aferições. O Quadro 11 apresenta os detalhes de cada componente.

Quadro 11 - Definições sobre tela de avaliação de trabalhos.

\begin{tabular}{|c|l|}
\hline Item & Definição \\
\hline 1 & $\begin{array}{l}\text { Listagem com os critérios estabelecidos para o evento de acordo com o tipo do trabalho julgado. Os } \\
\text { critérios "Apresentação oral", "Metodologia" e "Texto" foram concebidos pela interface apresentada } \\
\text { na figura 3; }\end{array}$ \\
\hline 2 & $\begin{array}{l}\text { Representa um critério que já foi avaliado, ou seja, o avaliador já atribuiu uma nota ao mesmo, e a } \\
\text { exemplo do que ocorre na listagem de trabalhos, a imagem à direita (bandeira verde) indica que o } \\
\text { item já foi avaliado; quando não avaliado, o item é apresentado na cor vermelha; }\end{array}$ \\
\hline 3 & $\begin{array}{l}\text { Representa o critério de avaliação corrente, ou seja, o item selecionado o qual o avaliador está } \\
\text { examinando; }\end{array}$ \\
\hline 4 & $\begin{array}{l}\text { Representa detalhes do critério selecionado; essas informações são providas pela interface } \\
\text { apresentada na figura 3, itens 5 e 6, respectivamente; }\end{array}$ \\
\hline 5 & $\begin{array}{l}\text { Informação textual que ajuda o avaliador a compreender melhor a nota atribuída. Além da } \\
\text { informação textual, uma borda colorida ao redor da nota também é projetada. O Quadro 12 } \\
\text { demonstra todos os sinais visuais disponíveis; }\end{array}$ \\
\hline 7 & $\begin{array}{l}\text { Componente para seleção da nota. Este componente apresenta notas com duas casas decimais } \\
\text { iniciando em 0,00 (zero) até a nota máxima 10,00 (dez), variando entre uma nota e outra em } 0,25 \\
\text { pontos; }\end{array}$ \\
\hline Botão para registrar uma nota. Ao clicar sobre este item, o sistema identifica se ainda existem \\
\hline
\end{tabular}

\begin{tabular}{l|l|l|l|l|l|l} 
(C) Rev. Inter. Educ. Sup. & Campinas, SP & v.2 & n.3 & p.501-517 & set./dez. 2016 & ISSN 2446-9424
\end{tabular} 


\begin{tabular}{|l|l|}
\hline critérios sem avaliação; caso existam redireciona para os mesmos, a fim de possibilitar o \\
julgamento. Caso todos os critérios estejam avaliados, então retorna-se à listagem de trabalhos, \\
como ilustra a figura 10.
\end{tabular}

Fonte: Elaboração dos autores.

Quadro 12 - Escalas de sinais visuais

\begin{tabular}{|l|l|l|} 
Situação & Faixa de nota & Cor \\
\hline Péssimo & Entre 0 e 2 & Preta \\
\hline Ruim & Entre 2 e 4 & Vermelha \\
Regular & Entre 4 e 6 & Amarela \\
\hline Bom & Entre 6 e 8 & Verde \\
\hline
\end{tabular}

Fonte: Elaboração dos autores.

Após proceder todas as avaliações, o avaliador deve realizar uma nova sincronização a fim de enviar seus julgamentos ao servidor para serem apurados.

\section{Considerações Finais}

O modelo tradicional de avaliação de trabalhos científicos geralmente faz uso de formulários impressos, alimentados manualmente pelos avaliadores. Com o término dos julgamentos, inicia-se outra tarefa manual, que é a apuração dos resultados, a qual se resume em somar a nota de todos os avaliadores separadamente, por trabalho e por áreas temáticas, criando um ranking com os melhores trabalhos.

A abordagem tradicional de avaliação, apesar de funcional, é bem mais demorada e envolve muitas pessoas no processo. Como já abordado, as TICs podem prover ferramentas que auxiliam em tarefas rotineiras, em gerar de conhecimento e, principalmente, integrando saberes.

Neste contexto, o Bookline surge como uma alternativa para gerenciar, agilizar e automatizar o processo avaliativo em eventos científicos, minimizando falhas na organização e otimizando a execução. Com o apoio desta ferramenta, as apurações ocorrem de forma automática e transparente, a organização se torna simplificada e não necessita do envolvimento de tantas pessoas. 


\section{Referências}

CARMO, João dos Santos; PRADO, Paulo Sérgio Teixeira do. Apresentação de trabalho em eventos científicos: comunicação oral e painéis. Interação em Psicologia, Curitiba, v. 9, n. 1, p. 131-142, 2005.

CAMPELLO, Bernadete Santos. Encontros científicos. In: CENDÒN, Beatriz Valadares; KREMER, Jeannette Marguerite (Org). Fontes de informação para pesquisadores e profissionais. Belo Horizonte: Ed. UFMG, 2000.

CENDÒN, Beatriz Valadares; KREMER, Jeannette Marguerite (Org). Fontes de informação para pesquisadores e profissionais. Belo Horizonte: Ed. UFMG, 2000.

KUHN, Thomas S. A. Introdução: Um Papel para a História. A Rota para a Ciência Normal. In: __ Estrutura das Revoluções Científicas: debates, Ciência. 5.d. São Paulo, S.P: Editora Perspectiva S.A, 1998. Cap.1.

LACERDA, Aureliana Lopes et al. A importância dos eventos científicos na formação acadêmica: estudantes de biblioteconomia. Revista ACB: Biblioteconomia em Santa Catarina, v. 13, n. 1, p. 130-144, 2008. Disponível em:

https://revista.acbsc.org.br/racb/article/view/553. Acesso em 20 de julho de 2016.

MEADOWS, Arthur Jack. Canais da comunicação científica. Brasília: Brinquet de Lemos Livros, 1999.

OLIVEIRA, C. C. et al. Ambientes Informativos de Aprendizagem: produção e avaliação de software educativo. Campinas: Papirus, 2001.

POBLACIÓN, Dinah Aguiar; NORONHA, Daisy Pires; CURRÁS, Emília. Literatura cinzenta versus literatura branca: transição dos autores das comunicações de eventos para produtores de artigos. Ciência da Informação, Brasília, v.25, p.228-42, 1996.

SCHIMIDT, Luciana; OHIRA, Maria Lourdes Blatt. Bibliotecas virtuais e digitais: análise das comunicações em eventos científicos (1995/2000). Ciência da Informação, Brasília: v.31, n.1, jan. 2002.

SOUZA, Renata Beduschi de. O uso das tecnologias na educação. Conteúdo exclusivo online, set. 2010. Revista Pátio. Disponível em: https://www.grupoa.com.br/revistapatio/Default.aspx. Acesso em 20 de julho de 2016.

SILVA, Marco. Educação Online: teorias, práticas, legislação e formação corporativa. 2.ed. Edições Loyola. São Paulo. 2003.

TARGINO, Maria das Graças. Comunicação científica: uma revisão de seus elementos básicos. Informação \& Sociedade: Estudos, João Pessoa, v.10, n.2, 2000.

VAlEnte, J. A. O uso inteligente do computador na educação. Revista Pedagógica Pátio.

\begin{tabular}{l|l|l|l|l|l|l} 
(C) Rev. Inter. Educ. Sup. & Campinas, SP & v.2 & n.3 & p.501-517 & set./dez. 2016 & ISSN 2446-9424
\end{tabular}


São Paulo: Artes Médicas Sul, p. 19-21, maio/jul. 1997. Disponível em: < www.unidavi.edu.br/ afischer/content/2002-Sep-27_19-57-37.pdf>. Acesso em: 20 jul. 2016. 